\title{
Study on Low Ecological Technology Strategy of Qiang Dwellings in Northwestern Sichuan
}

\author{
Gao Ming \\ Southwest University of Science and Technology ,School of Civil Engineering and Atchitecture, \\ Mianyang 621010, China; \\ Gm7161@163.com
}

\begin{abstract}
Keywords: Qiang Village Dwellings in Northwestern Sichuan, Low Technology,Ecological Strategy Abstract. Taking Taoping Qiang Dwellings in Li County, Aba Prefecture of Northwestern Sichuan as case, this paper analyzed low ecological technology strategy applied by Qiang Dwellings in Northwestern Sichuan for coping with alpine region, including regional environment strategy, architectural technology mode. It discussed the ecological strategy of the combination between regional architecture and natural environment \& terrain, which deserves research and reference in nowadays constructions.
\end{abstract}

\section{Introduction}

Due to inconvenient traffic, remote area and relatively closed blocking of information exchange with the outside, the buildings of inhabitation area of most Chinese minorities maintained good authenticity. Especially, residential buildings represented low ecological technology strategy characteristics. Taking Taoping Qiang Village in Northwestern Sichuan as case, it analyzed low ecological technology strategy in Qiang ethnic minority dwellings from regional environment strategy, architectural technology mode and spatial order system.

\section{Terrain Environment and Climatic Characteristics of Qiang Villages in Western Sichuan}

The highland in northwestern Sichuan is one geographical unit integrating complex landforms such as high mountains, subalpine, plateau, and river alley. It is the fall transition zone from Qinghai-Tibet Plateau to Chengdu Plain in Sichuan, belonging to plateau climate, which has high mountains and deep valleys. In addition, it is freezing, cold, windy with less rainfall, changeable in climate and has long sunshine duration, showing typical vertical climate and ecological characteristics.

The highland in northwestern Sichuan is the inhabitation corridor of eastern ethnic minorities in Hengduan Mountains, including Aba Tibetan and Qiang Autonomous Prefecture in Sichuan Province and Garze Tibetan Autonomous Prefecture, located at the upper reaches of Minjiang River in Sichuan Province. The Minjiang River and its tributary run across the fringe of Qinghai-Tibet plateau, causing high-mountain deep-valley terrain. Such deep valley in high mountains is called as valley by Qiang People, and the dwellings of Qiang ethnic minority is distributed in the valleys.

Taoping Qiang village located at Li County was the mountain pass and key defense area in Han Dynasty. In the east of Minjiang tributary and the north bank of Zanaogu River, it is river alluvial fan sloping filed, fronting water with hills on the back, facing south. It belongs to temperature climate with demarcated four seasons, which is windy and cold in winter with rare rainfall, strong sunshine, dry air and large day and night temperature difference. The rainfall is mainly concentrated in May-September. Therefore, site selection at river valley alluvial fan slope and fronting water with hills on the back is beneficial for withstanding monsoon in north direction. Moreover, facing river valley can avoid the perennial influence of east-west wind, and open gentle slope is beneficial for acquiring good sunshine. 


\section{Regional Environment Countermeasures}

Qiang ethnic minority generally resides near the mountain and by the water. Such clustering residence architectural complex is called as stockaded village in Qiang ethnic minority. Qiang village is not only the abode of Qiang ethnic minority, but also can embody its use function, architectural ecological design, architectural general layout, as well as the comprehensive use value of water, firefighting and war. The miracle road network, water network and roof of Taoping composes the aboveground, underground, and three-dimensional crossed road network and defense system, which is the peculiarity of Taoping Qiang village architectures.

\section{Adjusting Measures to Local Conditions and Site Selection Layout}

Taoping Qiang Village was constructed as per mountain trend, surrounded by green hills with back-high and front-low terrain, fronting water with hills on the back. A creek runs in front of the village, co-existing harmoniously with nature. Analyzing from modern ecology, hills on the back can block cold wind in winter, and fronting water can embrace wet cool breeze in summer and guarantee living water, which is beneficial for the development of agriculture and animal husbandry. Broad front forms excellent sunshine and ventilation environment, enclosed valley has the role of preventing wind and flood, forming excellent cycle ecological microclimate. (See Fig.1, Fig.2)

For sufficiently utilizing the limited plain terrain on mountain slope and closely combining with terrain, the adjustment on number of layers, storey height and terrace enables architecture to be low in front and high in back. Residing as per mountain can save large amounts of earthworks. The bottom layer is overhead utilizing natural ground as the residence of livestock, the middle layer is residence room, and the upper layer is storeroom. Most parts of Sichuan belong to subtropical humid monsoon climate, overhead bottom layer can resolve people's living problems under the conditions of not damaging the earth's surface. Meanwhile, it can increase the room's surface area, strengthen ventilation and heat dissipation, and improve residence environment.

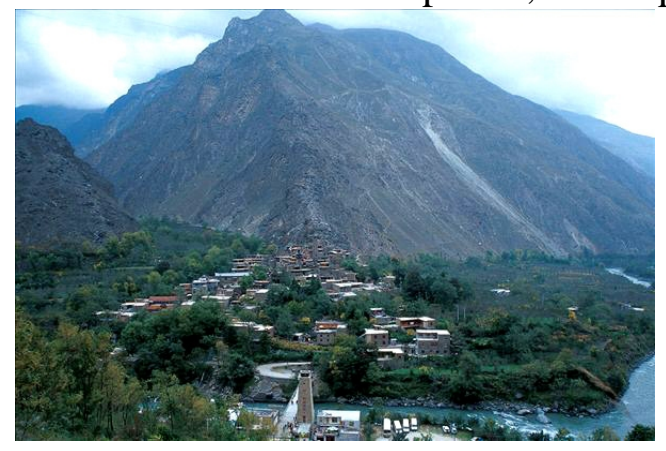

Fig. 1 Panorama of Taoping Qiang Village

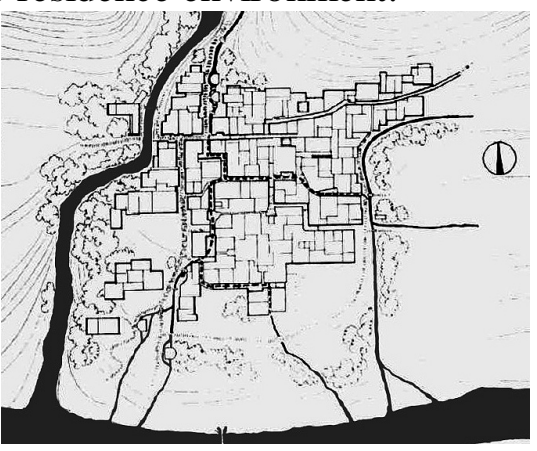

Fig. 2 General Layout of Taoping Qiang Village

\section{Dense Creation and Narrow Streets}

Taoping Qiang Village community is one closely concentrated entirety, aisle for passing was only left among architectures, and there is no strict ground open space. Concise layout is not only beneficial for saving plough, but also for withstanding large temperature difference climatic change in high altitude mountain area. Curve and narrow street space blocks the smooth pass of wind in lanes, and also provide pleasant shadow in scorching daytime. Heavy and sick wall gathers together, storing heat to the greatest extent after experiencing sufficient sunshine, which can let indoor temperature change be stable at night. The combination of fireplace and complex space is able to maintain indoor thermal stability. Intensive creation has universality in communities of high altitude mountain area in the southwest.

In addition, intensive architecture group layout is beneficial for creating platform suitable for people's activities in uneven mountain area. Qiang village dwellings are often of parallel contour line layout, descending following slope. The distance between households is very small, mostly at about $1 \mathrm{~m}$. Dense roofs are connected via beam and wood, creating one three-dimensional walk passageway in the second and the third layer elevation. 


\section{Architectural Technology Mode}

\section{"Air Space" and "Core" Space}

For adapting to severe environment, Qiang village tries best to decrease the maintenance on heat loss in structure, and the watchtower in Qiang village adopts air space creation mode. The so-called air space refers to the creation of a series of architectural affiliated space in the process of reaching the main use site via architectural building mode. In the process of reaching the core space-main room of Qiang people's dwellings, there are multiple layers: outdoor-thick stonewall-bottom layer livestock shed-second layer embraces the main room-main room-top layer cap room. The space of main room is encompassed, and its inside is separated by external severe environment. It prevents the access of hard light and thermal radiation, and preheats air at night, which can alleviate the loss of internal hot air, strengthen thermal stability in central room. Seen from the perspective of Physics, it is a good method of thermal insulation.

The watchtower of Qiang village mainly conducts ventilation and smoke discharge via skylight (See (See Fig.3). Smoke has the efficacy of consolidating wall, fumigating room, and moth proofing. The smoke generated in kitchen at the second floor has important protection role on wood component. Fumigation can dry wood component, thereby improving its durability. Qiang people are also able to control the direction of smoke via floor open holes, and smoke storage floor can reutilize cooking waste heat as heat source, not needing tobacco for specialized meat fumigation. Such green ideology and energy recycling technology deserves reference and research.

\section{Lighting, Ventilation and Wall Holes}

For adapting to alpine climate with large temperature difference, the enclosure system of Qiang Village buildings has thick walls and small windows, enabling the indoor to maintain relatively stable and suitable temperature. The side facing wind and backing sunshine basically does not need to open window or just open small window, so as to decrease the influence of cold airflow on indoor environment. The side backing wind and facing sunshine opens window appropriately, thereby acquiring necessary sunshine. In addition, the cross section of hall exhibits trapezoid, which is wide inside and narrow outside. The roof has cap room and threshing ground. Cap room shields the influence of cold wind on threshing ground, and the wall of cap room withstanding wind has 1-2m hole, which can be opened as per requirements, immediately acquiring strong ventilation effect.

Except closed form against severe environment, Qiang Village dwellings need appropriate opening to resolve lighting and ventilation problems. The sphenoid window holes (small outside and large inside) on thick walls have multiple functions such as lighting, defending against the cold, thermal insulation, ventilation, prevention of burglary, and defense. There is another important processing technique, i.e. the application of high side windows. At the intersection of vertical enclosure wall and horizontal roof, there are generally holes $(25-30 \mathrm{~cm}$ high and $50-60 \mathrm{~cm}$ wide) inserted with yellow thorns or oil bamboos. High side window can not only achieve excellent ventilation effect, but also maximally project light ray into the deep of room (See Fig.4).

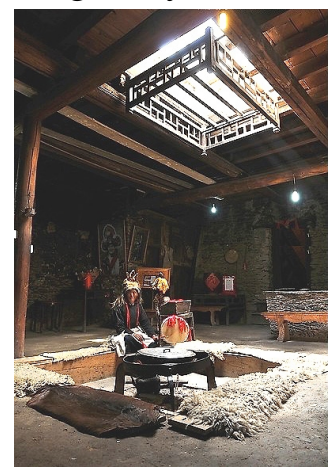

Fig. 3 Ventilation and Smoke Discharge of Skylight

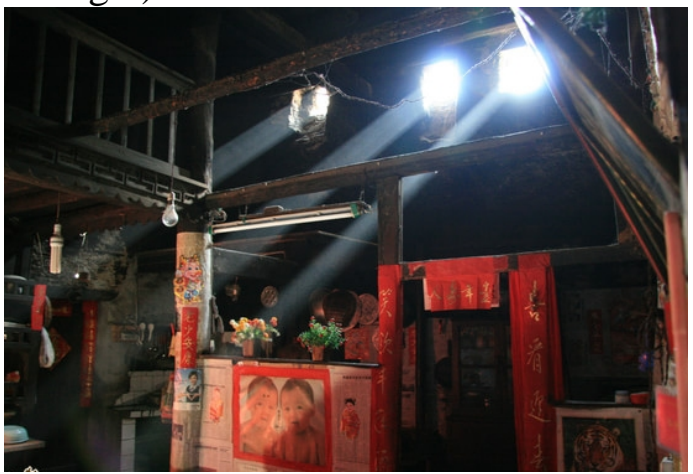

Fig. 4 High Side Windows

\section{Large Temperature Difference and Wall Structure}

The exterior walls of Taoping Qiang Village is constructed via cobbles and rubbles(See Fig.5), orderly mottled, drawing materials (soil, stone, maggin and some only use wood) closely. Firstly dig quadratic 
ditch (1-2m deep) at selected ground, and select large flag to build footing about three feet wide, and then use mixed yellow mud as plasma to glue rubbles. The stone wall is gradually thin from bottom to top and shrinking layer by layer. From bottom to top, the roof structure respectively includes girder, crevice layer, bamboo pole, yellow thorn, brown rake, and rammed earth floor. Composite material is beneficial for thermal insulation. In areas without rubbles, Qiang people use local yellow clay to ram house, and even ram high blockhouse for defense use. The construction form and characteristics of rammed earth dwelling is basically the same with masonry blockhouse. The village is one building complex integrating stone blockhouse and dwelling, and the firmness of rubble and yellow mud are intact after numerous earthquakes.

\section{Roof and Ground}

The climb of Taoping Qiang Village formed scattered stone built square bungalows, mostly in 3-storey and about $3 \mathrm{~m}$ in each storey. The underneath of roof platform is wood or slate, stretching out wall to form eave. The wood or slate is densely covered with limb or bamboo pole, and covered with loess and chicken manure to ram firmly, thickness $35 \mathrm{~cm}$, which has hole groove to drain water, not leaking rain and snow. Meanwhile, it can guarantee the comfortable indoor requirements of warm winter and cool summer. Roof platform is the site for threshing, basking grain, needlework, game and rest for children and the elderly. Some buildings are built with arcade (overhang) for intercourse. (See Fig.6)

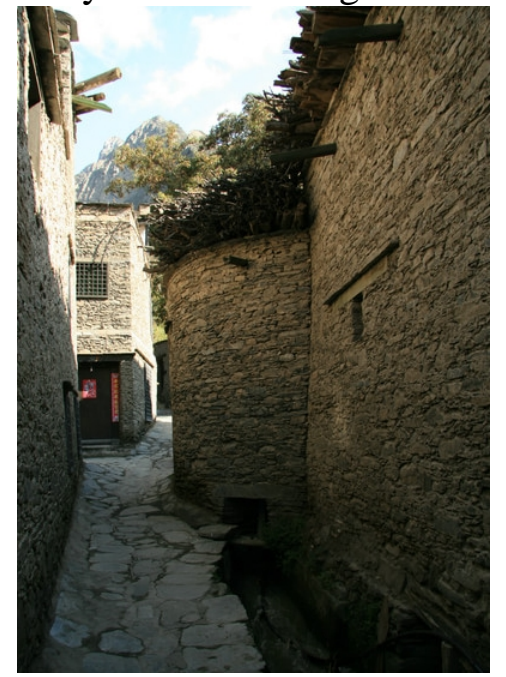

Fig. 5 Exterior wall with flaky materials Watchtower

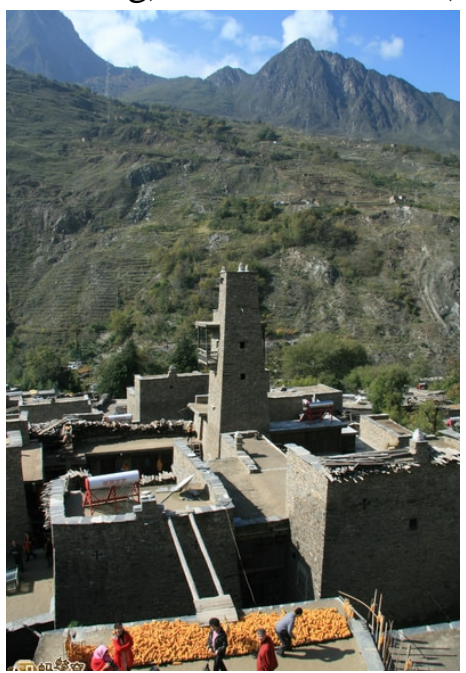

Fig. 6 The Section and Structural Map of Large

\section{Conclusion}

The regional environment countermeasures, architectural technology mode and spatial order system of Qiang village dwellings in western Sichuan is low ecological technology architectural logic and strategy, which are of the same strain with Qiang dwelling buildings. Taking a foothold in local regional environment, adjusting measures to local conditions, using local materials, and adopting suitable technologies, local craftsmen adopt traditional architectural technology for house-raising. It penetrates low ecological technology thinking, embodying outstanding and plain low ecological technology strategy, which has positive reference and learning value for buildings needed by the widespread and numerous low-income groups in China.

\section{References}

[1] Ji Fuzheng, Buildings of Chinese Qiang Ethnic Minority,M. Sichuan: Southwest Jiaotong University Press, 2000

[2] Ethnography editorial committee office, Historical Annals of Sichuan Nationalities (Research on Qiang Ethnic Minority),M. Sichuan: Sichuan Nationalities Publishing House, 1991 
[3] Mao Gang, Ecological Vision-Communities and Architectures in Southwestern High Altitude Mountainous Regions,M. Nanjing: published by Southeast University, 2003

[4] Ren Hao, Architectures and Villages of Qiang Ethnic Minority J . Architectural Journal, 2003 (8)

[5] Yu Zhihong, Study on Ecological Architectural Design Represented in Qiang Ethnic Minority Blockhouses ,J. Journal of Fujian University of Technology, 2006 